\title{
Declining Trends in the Provision of Prenatal Care Visits by Family Physicians
}

Donna Coben, MD, MSc

Andrew Coco, MD, MS

The Lancaster General Research Institute, and the Department of Family and Community Medicine, Lancaster General Hospital, Lancaster, Pennsylvania
AIC ournal Club selection see inside back cover or http://www. annfammed.org/AJC/.

Conflicts of interest: The authors bave no potential, perceived, or real conflicts of interest related to the study.

\section{CORRESPONDING AUTHOR}

Donna Cohen, MD, MSc

Medical Research Institute

555 North Duke St, PO Box 3555

Lancaster, PA 17604

docohen@lancastergeneral.org

\begin{abstract}
PURPOSE We wanted to measure trends in the proportion of prenatal visits provided by family physicians nationally for a 10-year period and determine characteristics of prenatal visits made to family physicians compared with visits made to obstetricians.
\end{abstract}

METHODS We analyzed the National Ambulatory Medical Care Survey to identify prenatal visits made to family physicians and obstetricians between 1995 and 2004. The primary outcome measure was the trend in proportion of prenatal visits seen by family physicians. Multivariate logistic regression analysis determined characteristics of a prenatal visit occurring with a family physician vs an obstetrician.

RESULTS A total of 6,203 records were included in the study, representing 244 million prenatal visits. The percentage of prenatal visits provided by family physicians decreased from $11.6 \%$ in $1995-1996$ to $6.1 \%$ in 2003-2004 ( $P=.02$ for trend). In non-metropolitan statistical areas, family physicians decreased their provision of prenatal visits from $38.6 \%$ in $1995-1996$ to $12.9 \%$ in $2003-2004$ ( $P=.03$ for trend). Prenatal visits made to family physicians were associated with location in a non-metropolitan statistical area (OR $=5.56 ; 95 \% \mathrm{Cl}, 3.23-9.62)$, Medicaid insurance $(\mathrm{OR}=1.76 ; 95 \% \mathrm{Cl}, 1.10-2.82)$, and younger maternal age (aged 30 years and older vs aged less than 24 years: $\mathrm{OR}=0.63 ; 95 \% \mathrm{Cl}, 0.41-0.95)$.

CONCLUSIONS Family physicians reduced their provision of prenatal visits by nearly $50 \%$ during a 10 -year period and at an even greater rate in rural, non-metropolitan statistical areas. These findings should be considered as family medicine considers the role of maternity care and strives to provide accessible prenatal services for all.

Ann Fam Med 2009;7:128-133. DOI: 10.1370/afm.916.

\section{INTRODUCTION}

A ccess to maternity care for women in the United States remains a public health concern. Previous studies have established the contribution of family physicians to maternity care, particularly in rural areas. ${ }^{1-8}$ A decline in maternity care clinicians in rural communities where physicians may be in short supply has also been associated with poorer perinatal outcomes. ${ }^{2,9-11}$

A large body of literature from the 1980s and 1990s documented a decline in the provision of maternity care by family physicians. ${ }^{1,2,10-17}$ Even though more recent evidence is sparse, the available evidence suggests that this decline has persisted. Data from the American Academy of Family Physicians indicates that in $1986,43 \%$ of responding family physicians performed deliveries compared with $28 \%$ of respondents in 2006 , although interpretation of these data are limited by a variable response rate. ${ }^{18}$ Guirguis-Blake et al showed that family physicians decreased their contribution nationally to prenatal care from $17.3 \%$ of total visits (between 1980 and 1992) to $10.2 \%$ of visits (between 1993 and 1999). ${ }^{19}$ No estimates of the percentage of family physicians who provide prenatal care since 1999 have been published. 
The purpose of our study was to (1) measure the trend in the proportion of prenatal visits made to family physicians during the 10 -year study period and (2) determine the characteristics of prenatal visits made to family physicians with visits made to obstetricians. We analyzed data from the National Ambulatory Medical Care Survey (NAMCS) from 1995 to 2004. Improved knowledge of the distribution and provision of prenatal visits will help clarify the contribution of family physicians to prenatal care and whether innovative steps need to be taken to meet the goals of high-quality, accessible pregnancy care for all US women.

\section{METHODS}

\section{National Ambulatory Medical Care Survey}

The NAMCS is administered by the National Center for Health Statistics (NCHS) for the Centers for Disease Control and Prevention (CDC). ${ }^{20}$ The NAMCS collects information on patient visits to office-based physician practices in the United States, including federally qualified health centers and nonfederal government clinics. The survey incorporates a multistage probability design to generate a population-based sample. The NCHS weights each sampled visit by taking into account practice location and physician specialty.

Physicians are randomly selected from the master files of the American Medical Association and the American Osteopathic Association. Each physician is randomly assigned to a 1 -week reporting period. During this period, data for a systematic random sample of visits are recorded by the physician or office staff on a standardized encounter form and checked for completeness by NCHS field staff.

The survey collected 266,629 patient records between 1995 and $2004 .{ }^{20}$ The participation rate of contacted physician practices in the NAMCS ranged from $63 \%$ in 1999 to $73 \%$ in 1995 . Quality control was performed using a 2 -way independent verification procedure for $10 \%$ of the sample records. In 2004, coding errors for various items ranged from $0 \%$ to $0.9 \%$.

The NCHS weights each visit to allow extrapolation to national estimates for all aspects of the survey. The weighing calculations account for practices that were invited to participate but declined to do so. National estimates are considered reliable with a standard error of $30 \%$ or less, which generally corresponds to a sample of at least 30 patient visits. ${ }^{21}$

\section{Study Variables}

Deidentified clinical and demographic data, including age, insurance status, and race, were collected for each visit. ${ }^{21}$ The NCHS institutional review board approved the protocol for the NAMCS, including a waiver of the requirement for informed consent. Physician and hospital variables include self-selected specialty. A midlevel clinician variable includes visits made to midwives, nurse-practitioners, and physicians' assistants. Clinical variables included the primary diagnosis and up to 2 secondary diagnoses coded according to the International Classification of Diseases (ICD-9-CM). ${ }^{22}$ The NCHS divides the country into 4 geographical regions: Northeast, South, Midwest, and West. Rural locations were identified based on the designations of non-metropolitan statistical area (non-MSA) by the US Office of Management and Budget. A metropolitan statistical area (MSA) is defined as a county or group of contiguous counties that contains at least 1 city with a population of 50,000 or more or an urbanized area with a metropolitan population greater than $100,000 .^{23}$

We examined all office visits with the primary diagnoses of normal pregnancy, high-risk pregnancy, and pregnancy-related complications, as outlined in detail in a related study. ${ }^{24(\mathrm{Fig} 1)}$ To capture prenatal diagnoses accurately, we included only visits in which the fifth digit of the 5-digit ICD-9-CM code was 3, corresponding to an antepartum condition. We eliminated visits to physicians whose specialty was not family medicine or obstetrics-gynecology. Visits to midlevel clinicians, including midwives, occurred in physicians' offices and did not include midlevel clinicians who were practicing independently.

\section{Statistical Analysis}

To assess changes in rates of prenatal visits over time, we used the $\chi^{2}$ test for linear trend. To decrease annual variation in visit estimates, we combined 2 successive years of data, as recommended by NCHS, for a total of 5, 2-year periods (1995-1996, 1997-1998, 1999-2000, 2001-2002, 2003-2004) for the trend analysis. ${ }^{21}$ All statistical trend tests take into account data from all 10 years, from 1995 through 2004

We calculated standard errors for all results as recommended by the $\mathrm{NCHS}^{21}$ using Stata software. To take into account the complex multistage sample design of the survey, Stata was programmed with the masked survey design variables that allow for making population estimates and generation of variance estimates which result in conservative tests of significance. ${ }^{25}$ We evaluated categorical variables with the $\chi^{2}$ test. All $P$ values are 2 -tailed $i P<.05$ was considered significant. Stata version 9 was used to analyze all data (StataCorp LP, College Station, Texas).

\section{RESULTS}

A total of 6,203 sample records met inclusion criteria for the study. These sample records represented an 
estimated 244.5 million prenatal visits in the United States between 1995 and 2004, with 222.5 million visits to obstetricians and 21 million visits to family physicians. The total number of prenatal visits per biannual period remained stable during the 10 -year period, with no declining trends.

Characteristics of the prenatal visits grouped by physician specialty are represented in Table 1. Visits to family physicians tended to be made by younger patients who had higher rates of Medicaid insurance and self-pay status. In addition, compared with visits to obstetricians, visits made to family physicians' offices were significantly more likely to occur in non-MSA locations $(P<.01)$. There was no significant difference in the rate of visits with high-risk diagnoses between family physicians and obstetricians $(P=.21)$.

\section{Trends in Proportion of Prenatal Visits by Specialty}

The primary outcome of analysis was the trend in the proportion of prenatal visits seen by family physicians, as shown in Figure 1. During the 10-year study period, the proportion of prenatal visits provided by family physicians in US offices decreased steadily from $11.6 \%$ in $1995-1996$ to $6.1 \%$ in 2003 2004 ( $P=.02$ for trend). In the rural, non-MSA locations, family physicians decreased their provision of prenatal visits at an even greater rate, from $38.6 \%$ in 1995-1996 to $12.9 \%$ in 2003-2004 ( $P=.03$ for trend) (Figure 2).

\section{Factors Independently Associated with Prenatal Visit Occurring with a Family Physician}

We used multivariate logistic regression modeling to determine factors associated with a prenatal visit occurring with a family physician vs an obstetrician (Table 2). In a model including demographic and insurance variables, independent predictors of a prenatal visit to a family physician were non-MSA location (vs MSA location: $\mathrm{OR}=5.56$; 95\% CI, 3.23-9.62), Medicaid insurance (vs private insurance: $\mathrm{OR}=1.76$; 95\% CI, 1.10-2.82), biennial period (per 2-year period:
Table 1. Characteristics of Prenatal Visits to Family Physicians and Obstetricians, 1995-2004 ( $N=6,203)$

\begin{tabular}{|c|c|c|c|}
\hline \multirow[b]{2}{*}{ Patient Characteristics } & \multicolumn{2}{|c|}{ Proportion of Visits (\%) } & \multirow[b]{2}{*}{$P$ Value } \\
\hline & $\begin{array}{l}\text { Family Physician } \\
(n=481)\end{array}$ & $\begin{array}{l}\text { Obstetrician } \\
(\mathrm{n}=5,722)\end{array}$ & \\
\hline \multicolumn{4}{|l|}{ Age, years } \\
\hline$<24$ & 47.0 & 31.2 & $<.01$ \\
\hline $24-30$ & 31.6 & 33.6 & \\
\hline$>30$ & 21.4 & 35.2 & \\
\hline \multicolumn{4}{|l|}{ Race } \\
\hline White & 87.8 & 83.0 & .09 \\
\hline Black & 7.0 & 11.8 & \\
\hline Asian and other ethnicity & 5.2 & 5.2 & \\
\hline Latino & 17.6 & 14.5 & .39 \\
\hline \multicolumn{4}{|l|}{ Health insurance } \\
\hline Private & 49.3 & 63.9 & $<.01$ \\
\hline Medicaid & 36.5 & 21.0 & \\
\hline Self-pay & 4.7 & 2.7 & \\
\hline Other & 9.5 & 12.4 & \\
\hline \multicolumn{4}{|l|}{ Geographic region } \\
\hline Northeast & 9.0 & 14.0 & .07 \\
\hline Midwest & 37.5 & 23.8 & \\
\hline South & 27.4 & 37.8 & \\
\hline West & 26.1 & 24.4 & \\
\hline \multicolumn{4}{|l|}{ Geographic entity } \\
\hline $\begin{array}{l}\text { Non-metropolitan } \\
\text { statistical area }\end{array}$ & 46.0 & 12.2 & $<.01$ \\
\hline \multicolumn{4}{|l|}{ Diagnoses } \\
\hline High-risk condition & 15.5 & 12.9 & .21 \\
\hline
\end{tabular}

Figure 1. Proportion of national prenatal visits occurring in family physicians' offices, 1995-2004.

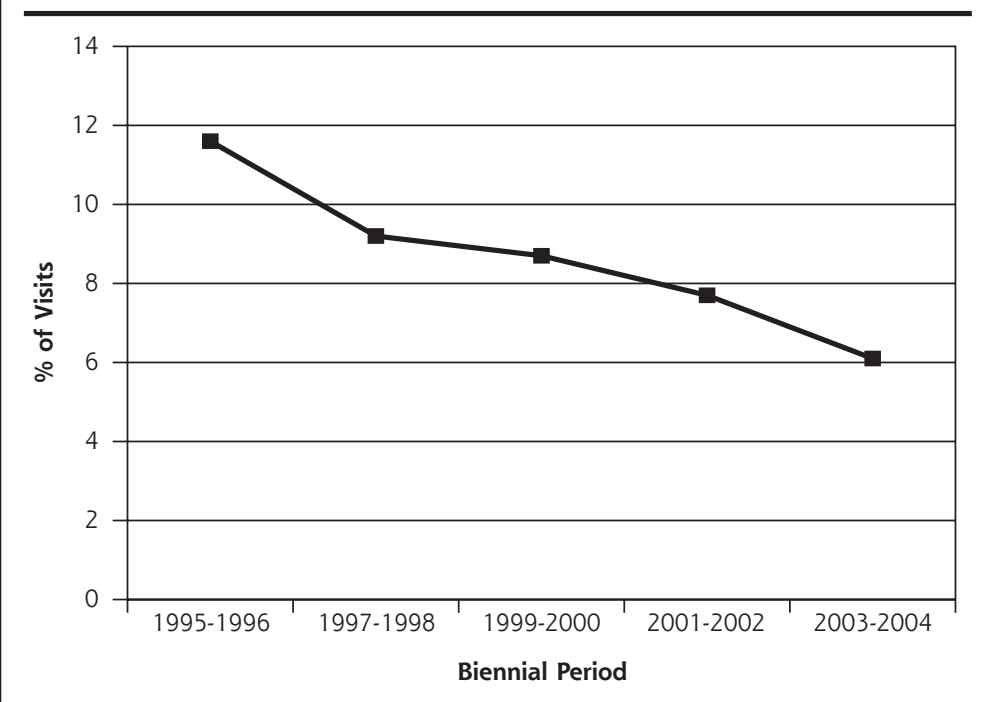

Note: National estimates based on 6,203 prenatal visits in the National Ambulatory Medical Care Survey, 1995-2004. For trend: $P<.02$
$\mathrm{OR}=0.81 ; 95 \% \mathrm{CI}, 0.68-0.97)$, and age younger than 30 years (aged $>30$ year vs aged $<24$ years: $\mathrm{OR}=0.63$; $95 \% \mathrm{CI}, 0.41-0.95)$. During the study period, the 
Figure 2. Proportion of prenatal visits occurring in family physicians' offices in non-MSA areas, 1995-2004.

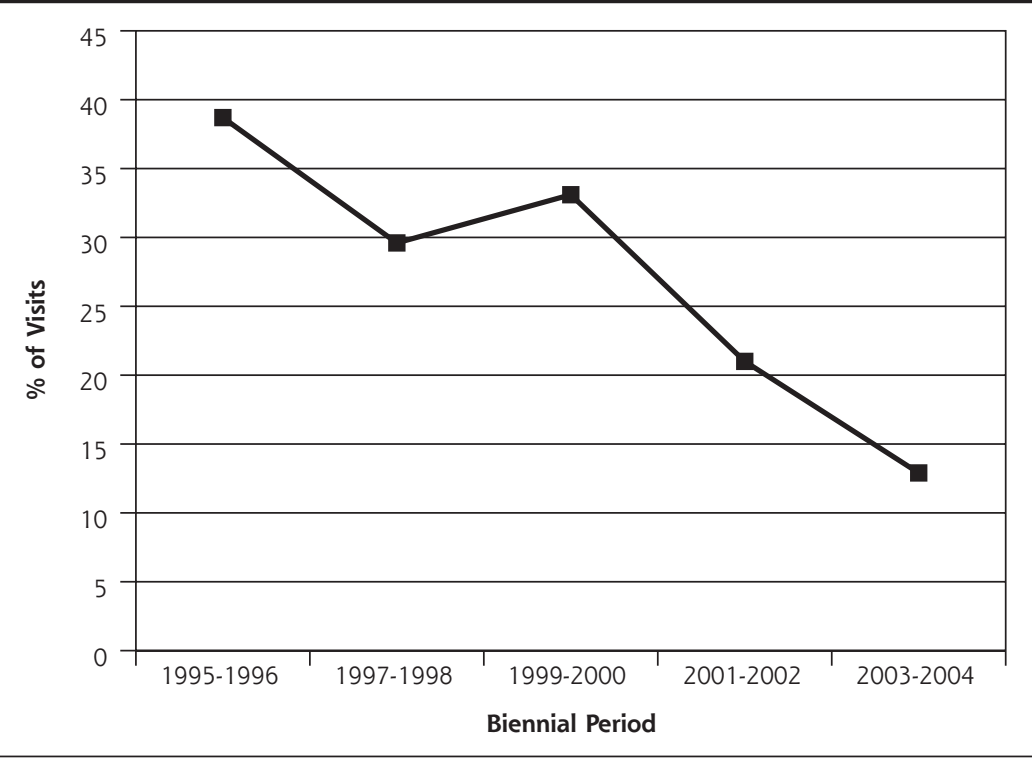

Note: national estimates based on 925 prenatal visits in non-metropolitan statistical areas, from the National Ambulatory Medical Care Survey, $1995-2004$. For trend: $P=.03$.

Table 2. Multivariate Logistic Regression Model Predicting Whether the Prenatal Visit Occurred With a Family Physician vs an Obstetrician

\begin{tabular}{lcc}
\hline Predictor Variable & $\begin{array}{c}\text { Unadjusted } \\
\text { Odds Ratio (95\% Cl) }\end{array}$ & $\begin{array}{c}\text { Adjusteda }^{\mathbf{9}} \\
\text { Odds Ratio (95\% CI) }\end{array}$ \\
\hline $\begin{array}{l}\text { Non-MSA (vs MSA) } \\
\text { Biennial period, per 2 years }\end{array}$ & $0.13(3.69-10.19)$ & $5.56(3.23-9.62)$ \\
Age, years & $0.81(0.68-0.97)$ \\
$>30$ & $0.40(0.27-0.60)$ & $0.63(0.41-0.95)$ \\
$24-30$ & $0.62(0.46-0.83)$ & $0.80(0.58-1.08)$ \\
$<24$ & 1.00 & 1.00 \\
Medicaid insurance & $2.25(1.46-3.45)$ & $1.76(1.10-2.82)$ \\
Self-pay status & $2.26(1.24-4.12)$ & $1.87(0.95-3.67)$ \\
Private insurance & 1.00 & 1.00 \\
\hline Cl = confidence interval; MSA = metropolitan statistical area. & \\
a Odds ratio adjusted for all listed variables plus race, geographic region, and high-risk diagnoses.
\end{tabular}

a low-risk diagnosis showed a similar decline, decreasing from $10.7 \%$ in $1995-1996$ to $5.3 \%$ in 2003-2004 ( $P=.03$ for trend).

In addition, it was believed that another factor contributing to the decline in visits to family physicians might be Medicaid insurance, which potentially may represent a population more likely to enter prenatal care late or receive fewer prenatal visits per pregnancy. We found that the proportion of total prenatal visits by women with Medicaid insurance remained stable during the 10 -year period, ranging from $22.6 \%$ in $1995-1996$ to $28.0 \%$ in 2003-2004 $(P=.17)$. Similarly, the proportion of women with Medicaid insurance who made prenatal visits to family physicians did not significantly change during the 10 -year period $(49.8 \%$ in $1995-1996$ to $31.9 \%$ in 2003 $2004{ }_{i} P=.20$ for trend).

\section{Prenatal Visits Made to Midlevel Clinicians}

Visits made to midlevel clinicians (midwives, nurse-practitioners, and physicians' assistants) accounted for 201 of the total 6,203 prenatal visits, with $98.4 \%$ of these visits occurring in obstetricians' offices. The proportion of prenatal visits made to midlevel clinicians remained stable, from $3.2 \%$ in $1995-1996$ to $4.4 \%$ in 2003-2004 ( $P=.73$ for trend). proportion of visits occurring with family physicians decreased by $19 \%$ every 2 years (Table 2 ).

We performed a series of analyses to better characterize and understand the declining trend in prenatal visits made to family physicians during the study period. We limited the sample to prenatal visits with a low-risk diagnosis based on ICD-9-CM code $(\mathrm{n}=5,429)$, with the thought that a woman with a high-risk diagnosis may make a greater number of prenatal visits and therefore contribute to an increased proportion of visits made to obstetricians' offices. During the 10-year study period, however, the proportion of prenatal visits to family physicians by women with

\section{DISCUSSION}

This study shows that family physicians have markedly reduced their provision of outpatient, prenatal visits by almost $50 \%$ over a 10 -year period. We also found that family physicians are more likely than obstetricians to provide prenatal visits to women who are younger, live in rural areas, or have Medicaid insurance.

Family medicine has long been considered to be an important source of maternity care, particularly in rural and underserved communities. ${ }^{1-8}$ Our study delineated the contribution of family physicians to prenatal care of the underserved, with one-third of prenatal 
visits to family physicians ensured by Medicaid. If the provision of prenatal services by family physicians continues to decline at the documented rate, however, it may become difficult to develop sustainable models for inclusion of maternity care in future practice, which ultimately may affect women's access to prenatal care in communities throughout the United States.

Ongoing decline in prenatal services by family physicians may have further widespread implications for care of children and reproductive-age women. Recent studies have shown that family physicians are providing a smaller proportion of outpatient care for children compared with 10 years ago. ${ }^{26,27}$ One explanation for this decline in pediatric care may be the decreasing proportion of prenatal care by family physicians, who often continue to care for the woman and her newborn after delivery. We are currently pursuing further analyses to examine trends in the provision of well-infant and postpartum care by specialty and to determine whether these services are, in fact, related to the declining provision of prenatal visits.

Our findings have implications for future family medicine training, as well. As family physicians continue to decrease their provision of maternity care, it may prove challenging to support family medicinebased curriculum, recruit faculty members, identify community role models, or develop sustainable models for residency graduates to include maternity care within their own practices, leading to further declines in accessible prenatal care physicians.

Finally, our study findings have implications at the public health level. Family medicine has long been considered to be an important source of maternity care in rural and underserved areas. ${ }^{1-8}$ Our data indicate that in non-MSAs a prenatal visit was 5.56 times more likely to occur with a family physician compared with an obstetrician (Table 2). It is in these non-MSAs, however, that the provision of care by family physicians declined significantly during the 10-year period, and at an even greater rate than that experienced in the MSAs (Figure 2). Although we are unable to quantify how the decline in prenatal visits by family physicians within non-MSAs specifically affects access to care within these regions, it is unlikely that the services once provided by family physicians in the most rural areas have been completely absorbed by obstetricians.

One potential explanation for this decline may be factors that are out of family physicians' control, such as closure of maternity wards or rural hospitals in these locations. Although the database is unable to directly address this information, we examined the distribution of total prenatal visits occurring in nonMSA locations over the 10-year period and found that the proportion of prenatal visits, in fact, remained stable from $9.7 \%$ in $1995-1996$ to $14.1 \%$ in $2003-2004$ ( $P=.83$ for trend). Further research is needed to quantify the impact that the loss of prenatal care visits by family physicians in rural and underserved communities may have on access to care

Our analysis of this nationally representative database has several inherent limitations. In this database, rural status was considered to be non-MSA, as defined by the US Office of Management and Budget. ${ }^{23}$ This designation, however, occurs at the county level and may actually misclassify smaller, rural areas as urban if they are located within a county considered to be a MSA. Second, there were no outcome data available to determine whether these trends are associated with maternal or fetal outcomes. Moreover, although NAMCS provides data on outpatient prenatal visits made to federally qualified community health centers, this proportion may be undersampled within the database, and prenatal care by family physicians in federally qualified health centers could therefore be underestimated.

Finally, the NAMCS database contains limited data on the contribution of midwives to outpatient prenatal visits. The variable includes all midlevel clinicians (midwives, nurse-practitioners, and physicians' assistants), and visits made to these clinicians are occurring within physician practices rather than independently functioning midwives or nurse-practitioners' offices. Few data exist describing national trends in the contribution of midwives to prenatal care. The most recent data from the National Center for Health Statistics indicates, however, that in 2005 certified nurse-midwives attended 306,377 of the total 4,138,349 births in the United States. ${ }^{28}$ If one were to estimate roughly 10 prenatal visits per delivery, yielding an approximate 3.1 million prenatal visits, prenatal care by midwives would still not account for the decline in prenatal visits by family physicians documented in this study.

In conclusion, this study provides evidence that family physicians have substantially reduced their contribution to prenatal care visits during the past decade. Future studies are needed to better understand the effects and the reasons behind this shift from family physicians to obstetricians in order to ensure adequate access to prenatal care for all women in the United States, particularly those in rural and underserved populations.

To read or post commentaries in response to this article, see it online at http://www.annfammed.org/cgi/content/full/7/2/128.

Key words: Prenatal care/trends; maternity care; pregnancy care; family medicine; residency

A version of this paper was presented at the 2008 STFM Annual Conference, October 30-November 2, Baltimore, Maryland. 


\section{References}

1. Institute of Medicine. Medical Professional Liability and the Delivery of Obstetrical Care. Vols I and II. Washington, DC: National Academy Press; 1989.

2. Rosenblatt RA, Detering B. Changing patterns of obstetric practice in Washington State: The impact of tort reform. Fam Med. 1988;20(2):101-107.

3. Nesbitt TS, Baldwin LM. Access to obstetric care. Prim Care. 1993; 20(3):509-522.

4. Congress of the United States. Health Care in Rural America. Washington, DC: Office of Technology Assessment; 1990.

5. Kruse J, Phillips D, Wesley RM. Factors influencing changes in obstetric care provided by family physicians: a national study. J Fam Pract. 1989;28(5):597-602.

6. Hueston WJ. Impact of a family physician-staffed maternity center on obstetric services in a rural region. J Fam Pract. 1991;32(1):76-80

7. Pathman D, Tropman S. Obstetrical practice among new rural family physicians. J Fam Pract. 1995;40(5):457-464.

8. Cohen D, Guirguis-Blake J, Jack B, et al. Family physicians make a substantial contribution to maternity care: the case of the State of Maine. Am Fam Physician. 2003;68(3):405.

9. Nesbitt TS, Connell FA, Hart LG, et al. Access to obstetric care in rural areas: effect on birth outcomes. Am J Public Health. 1990; 80(7):814-818.

10. Allen DI, Kamradt JM. Relationship of infant mortality to the availability of obstetrical care in Indiana. J Fam Pract. 1991;33(6):609-613.

11. Rosenblatt RA, Wright CL. Rising malpractice premiums and obstetrical practice patterns: The impact of family physicians in Washington State. West J Med. 1987;146(2):246-248.

12. Balaban DJ, Rosenthal MP, Ungemack JA, Carlson BL, Zervanos NJ. Obstetric care among family physicians in Pennsylvania: trends, association with residency training and policy implications. J Fam Pract. 1990;31(3):281-286.

13. Schmittling G, Tosu C. Obstetrical privileges for family physicians: A national study. J Fam Pract. 1989;29(2):179-184.

14. Clinton C, Schmittling G, Stern TL, Black RR. Hospital privileges for family physicians: A national study of office based members of the American Academy of Family Physicians. J Fam Pract. 1981;13(3):361-371.

15. Smith MA, Green LA, Schwenk TL. Family practice obstetrics in Michigan: factors affecting physician participation. J Fam Pract. 1989;28(4):433-437.
16. Smucker DR. Obstetrics in family practice in the state of Ohio. J Fam Pract. 1988;26(2):165-168.

17. Gordon RJ, McMullen G, Weiss BD, et al. The effect of malpractice liability on the delivery of rural obstetric care. J Rural Health. $1987 ; 3(1): 7-13$

18. American Academy of Family Physicians. Facts about family medicine practice profile of family physicians, December 31, 2006. http://www.aafp.org/online/en/home/aboutus/specialty/facts/4.html. Accessed Aug 23, 2007.

19. Guirguis-Blake J, Fryer GE, Deutchman M, Green LA, Dovey SM, Phillips RL. Family physicians' declining contribution to prenatal care in the United States. Am Fam Physician. 2002;66(12):2192.

20. Hing E, Cherry DK, Woodwell DA. National Ambulatory Medical Care Survey: 2004 Summary: Advance Data From Vital and Health Statistics: No. 374. Hyattsville, MD: National Center for Health Statistics; 2006.

21. National Center for Health Statistics. Public Use Microdata File Documentation, National Ambulatory Medical Care Survey, 2004. Hyattsville, MD: National Technical Information Service; 2006.

22. US Department of Health and Human Services. Centers for Disease Control and Prevention. International Classification of Disease, Ninth Revision, Clinical Modification. Hyattsville, MD: National Center for Health Statistics; 2007. http://www.cdc.gov/nchs/icd9.htm. Accessed Apr 2007.

23. Office of Management and Budget. Standards for defining metropolitan and micropolitan statistical areas, December 2000. http:// www.whitehouse.gov/omb/fedreg/metroareas122700.pdf. Accessed Sep 1, 2007.

24. Coco AS. How often do physicians address other medical problems while providing prenatal care? Ann Fam Med. 2009;7(2)134-138.

25. Hing E, Gousen S, Shimizu I, Burt C. Guide to using masked design variables to estimate standard errors in public use files of the National Ambulatory Medical Care Survey and the National Hospital Ambulatory Medical Care Survey. Inquiry. 2003;40(4):401-415.

26. Freed GL, Nahra TA, Wheeler JRC. Which physicians are providing health care to America's children? Trends and changes over the past 20 years. Arch Pediatr Adolesc Med. 2004;158(1):22-26.

27. The diminishing role of family physicians in caring for children. Am Fam Physician. 2006;73(9):1518.

28. Martin JA, Hamilton BE, Sutton PD, et al. Births: Final Data for 2005. National Vital Statistics Reports; vol 56 no 6. Hyattsville, MD: National Center for Health Statistics; 2007. 